\section{SAT0454 FINGER FLEXOR TENDON PULLEY COMPLEX INVOLVEMENT IN PSA: AN HIGH RESOLUTION ULTRASONOGRAPHIC STUDY}

I. Tinazzi ${ }^{1}$, A. Marchetta ${ }^{2}$, D. Chessa ${ }^{3}$, D. Mc Gonagle ${ }^{4}$, P. Macchioni ${ }^{5}{ }^{1}$ UOS Reumatologia, Ospedale Sacro Cuore-Don Calabria, Negar (Verona); ${ }^{2}$ Ospedale Sacro Cuore Negrar (Verona), Negrar Verona; ${ }^{3}$ Ospedale Paolo Dettori, Tempio Pausania (OT), Italy; ${ }^{4}$ Leeds Institute of Rheumatic and Muscoloskeletal Medicine, Leeds, United Kingdom; ${ }^{5}$ Ospedale S.Maria Nuova UOC Reumatologia, Reggio Emilia, Italy

Background: Psoriatic Arthritis (PsA) is often associated with hand involvement including synovitis and tenosynovitis and dactylitis. At the micro anatomical level PsA is strongly linked to disease localisation to entheses and other sites of high mechanical stressing. Recently high resolution MRI has shown prominent abnormalities at the mini-entheses of the flexor tendon pulleys, a site of high physical stressing during finger flexion

Objectives: This study tested the hypothesis that sonographic abnormalities were common at the hand flexor tendon mini-entheses in PsA including the A1, A2 and A4 in patients without active hand arthritis or dactylitis at the moment of ultrasound (US) scanning

Methods: Consecutive patients affected by psoriasis ( $\mathrm{PsO}$ (23 cases), PsA (17) and healthy controls (HC) (19) were collected. The demographic charateristics are shown in Table 1. The cases were matched for sex, age and BMI. We excluded PsA patients with active arthritis or dactylitis at the moment of US study, the majority being under therapy with conventional DMARDs. The 2nd to 4th flexor tendons of the dominant hand were scanned with a high resolution linear probe (10-22 MHz) using an Esaote MyLab Twice machine. The sonograrapher was expert in muscolo skeletal ultrasound (MSKUS) and was blinded to the clinical details. The following changes were scored: tenosynovitis, A1, A2 and A4 pulley tendon thickness and pseudotensynovitis (peritendinous oedema). Pulleys were explored with transverse e longitudinal scan

Results: The A1, A2 and A4 pulleys were significantly thicker in PsA compared to $\mathrm{PsO}$ and healthy controls measuring both longitudinal and transverse scan (table 2 shows mean $\pm S D$ value of transverse measures). In PsA patients A1, A2 and A4 pulleys thickness were above than the 95th percentile of HCs values respectively in $84 \%, 80 \%$ and $100 \%$ of cases.Considering $\mathrm{HCs}$ and PsA we found that having a A1 thickness over the 95th percentile of HCs shows a sensibility of $82 \%$ and specificity of $100 \%$ for PsA. Using ROC curve analysis we found that the presence of one A1 thickness over the 95th percentile of HCs have a sensibility of $82 \%$ and specificity of $100 \%$ for PsA. Peritendinous oedema evaluated scanning the palmar side of proximal and intermediate phalanx was common in PsA patients (6/17) and absent in $\mathrm{PsO}$ and $\mathrm{HCs}$

\section{Table 1 Demographic data}

\begin{tabular}{lccc}
\hline & Healthy $(\mathrm{n} \mathrm{19)}$ & $\mathrm{PsO}(\mathrm{n} \mathrm{23})$ & $\mathrm{PsA}(\mathrm{n} 17)$ \\
\hline $\mathrm{M} / \mathrm{F}$ & $7 / 11(39 \% 61 \%)$ & $9 / 14(40 \% 60 \%)$ & $12 / 570 \% 30 \%$ \\
Age $(\mathrm{y})$ med \pm SD & $57 \pm 12$ & $56 \pm 9$ & $56 \pm 6$ \\
$\mathrm{BMl}$ med \pm SD & $25.5 \pm 4.0$ & $25.9 \pm 3.2$ & $28 \pm 3$ \\
Nail involvment & 0 & $1(4 \%)$ & $8(47 \%)$ \\
Previous dactylitis & 0 & $1(4 \%)$ & $8(47 \%)$ \\
MS $>30$ ' & 0 & 0 & $9(53 \%)$ \\
Previous trigger finger & 0 & $7(32 \%)$ & $8(47 \%)$ \\
\hline
\end{tabular}

Table 2 Transverse measures of pulleys thickness $(\mathrm{mm})$

\begin{tabular}{lccc}
\hline & PsA & PsO & HCs \\
\hline A1 & $0.61 \pm 0.15$ & $0.40 \pm 0.10$ & $0.33 \pm 0.08$ \\
A2 & $0.56 \pm 0.11$ & $0.40 \pm 0.10$ & $0.34 \pm 0.07$ \\
A4 & $0.50 \pm 0.13$ & $0.33 \pm 0.05$ & $0.30 \pm 0.02$ \\
\hline
\end{tabular}

Conclusions: This study suggests that PsA cases have a much higher burden of abnormalities in the mini-entheses of the flexor tendons on the hand. With the improving resolution and capabilities of MKUS these findings may be relevant to understand the involvment of flexor tendon in PsA expecially in sites with high mechanical stressing. Measuring A1, A2 and A4 thickness could be useful in detecting PsA cases without clinical signs of sinovitis or dactylitis

Disclosure of Interest: None declared

DOI: 10.1136/annrheumdis-2017-eular.6777

\section{SAT0455 IMPACT OF PSORIATIC ARTHRITIS IN THE WORKPLACE: RESULTS OF THE FRENCH SURVEY PSOPRO}

P. Claudepierre ${ }^{1}$, I. Bonnet $^{1}$, Y. Roquelaure ${ }^{2}$, P. Levy ${ }^{3}$, R. Aubert ${ }^{4}$ H. Bachelez ${ }^{5} .{ }^{1}$ Rheumatology, CHU Henri Mondor Créteil, Cretell; ${ }^{2}$ Medicine and Occupational Health, CHU Angers, Angers; ${ }^{3}$ Economics, Université Paris-Dauphine, PSL Research University, LEDa [LEGOS]; ${ }^{*}$ Patient advocacy groups France Psoriasis; ${ }^{5}$ Dermatology, AP-HP Hôpital Saint-Louis, Sorbonne Paris Cité Université Paris Diderot, Paris, France

Objectives: The PsoPRO (Psoriasis \& PROfessional life) survey, run under the aegis of the patient advocacy groups France Psoriasis, was aimed at measuring, in comparison to the general population, the impacts of psoriasis occurring alone ( $\mathrm{PsO})$ or concurring with psoriatic arthritis ( $\mathrm{PsO}+\mathrm{PsA})$ on patients' working life. Methods: From 13/07/16 to 08/08/16, 714 PsO patients, 81 of whom were under systemic treatment (PsO-ST), and 84 patients $\mathrm{PsO}+\mathrm{PsA}$ were surveyed using a questionnaire drawn up by a multi-disciplinary scientific committee and conducted via the Internet. In addition to medical and professional characteristics, patients provided their recent absenteeism and presenteeism data, using a WPAI-PSO standardized self-questionnaire, as well as information about the interactions between psoriasis and their working life. Using the Student, Chi-deux and Fischer tests, patients were compared with a sample of 604 working respondents representative of the French population and questioned about the impact of possible health problems on their working life.

Results: The socio-demographic characteristics of the control group were similar to those of the total patient population with psoriasis, although men were slightly over-represented in the latter group. The duration of disease and cutaneous and rheumatismal locations were in line with those usually found in the literature. The unemployment rate over the previous 5 years and number of days of medical leave over the previous 12 months was higher in the PsO+PsA group as compared to the control group (Table 1). In the sub-group reporting a flare-up at the time of the survey, the impact of the disease on absenteeism, presenteeism and productivity was significantly higher in PsO-ST and PsO+PsA patients (Figure 1). Despite this, PsO-ST and PsO+PsA patients reported greater attachment to their work than did those in the control group (Table 1).

Table 1. Impact of psoriasis and psoriatic arthritis on functioning in the workplace and attachment to work

\begin{tabular}{|c|c|c|c|c|}
\hline & Control group & $\mathrm{PsO}$ & PsO-ST & $\mathrm{PsO}+\mathrm{PsA}$ \\
\hline Unemployment over the past 5 years, $\%$ (n) & $31(187)$ & $34(243)$ & $41(33)$ & $57^{\star}(42)$ \\
\hline Number of days of medical leave over past & & & & \\
\hline 12 months, $\mathrm{n}$ & 11 & 6 & 6 & $17^{\star}$ \\
\hline $\begin{array}{l}\text { Work considered more important than other } \\
\text { aspects of life, \% ( } n \text { ) }\end{array}$ & $8(45)$ & $10(62)$ & $28^{\star}(20)$ & $25^{*}(17)$ \\
\hline $\begin{array}{l}\text { Work considered less important than other } \\
\text { aspects of life \% (n) }\end{array}$ & $42(236)$ & $49^{\star}(301)$ & $21^{\star}(15)$ & $27^{\star}(18)$ \\
\hline
\end{tabular}
treatment; PsO+PsA: psoriasis and psoriatic arthritis.

Eigure - Impact of psoriasis and psoriatic arthritis on absenteeism, presenteeism and productivity over the past 7 das based on WPAI-PSO scores. " $\mathrm{p}<0.05$ versus control group respondents $\mathrm{PsO}$ : psoriasis; PSO-ST: psoriasis under systemic treatment;
$\mathrm{PsO}+\mathrm{PSA}$ : psoriasis and psoriatic arthritis
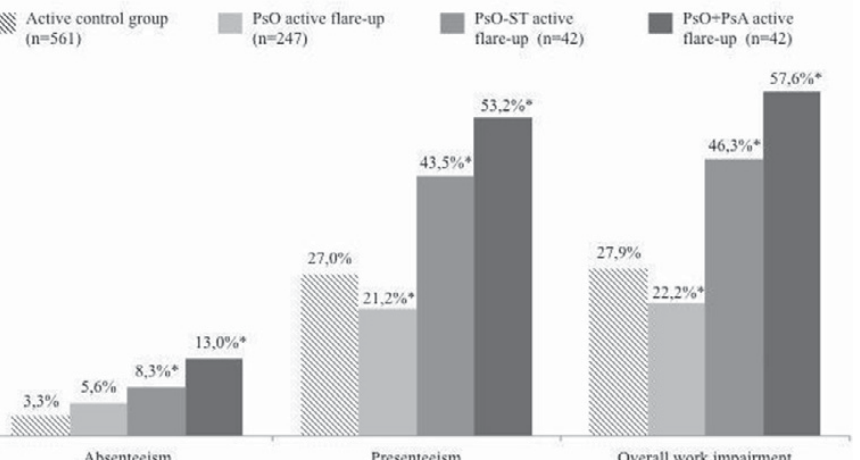

Conclusions: In patients with $\mathrm{PsO}$, placement under systemic treatment or the co-existence of PSA appears to be associated with greater impact on patients' working life, though they also reported higher attachment to their work. Close supervision and appropriate care in PSO patients developing PSA should limit these impacts.

Acknowledgements: This survey was made possible by funding from Celgene France and participation of the patient advocacy groups France Psoriasis.

Disclosure of Interest: P. CLAUDEPIERRE Grant/research support from: AbbVie, MSD, Roche, Pfizer, Consultant for: AbbVie, BMS, Celgene, Janssen, MSD, Novartis, Pfizer, Roche, UCB, I. BONNET: None declared, Y. ROQUELAURE Consultant for: Abbott, Celgene, P. LEVY Consultant for: AbbVie, Actelion, Amgen, Anergis, Astellas, Bayer, Becton Dickinson, Biogen, BMS, Conceptus, DaïchiSankyo, Eli Lilly, EOS, Gilead, GSK, Hospira, Impeto Médical, Janssen, MSD, Mundipharma, Novartis, Novo Nordisk, Roche, Sanofi Pasteur MSD, Stallergènes. H., R. AUBERT: None declared, H. BACHELEZ Grant/research support from: Pfizer, Consultant for: Abbvie, Actelion, Amgen, Boehringer, Celgene, Eli- Lilly, Janssen, Leo Pharma, Novartis, Pfizer, Takeda, Abbott, Merck Serono, Roche, Schering-Plough, Wyeth

DOI: 10.1136/annrheumdis-2017-eular.4433

\section{SAT0456 THERAPY MODIFICATIONS AMONG PATIENTS WITH PSORIATIC ARTHRITIS TREATED WITH A BIOLOGIC IN THE UNITED STATES - DESCRIPTIVE ANALYSES FROM AN ADMINISTRATIVE CLAIMS DATABASE}

J.A. Walsh ${ }^{1}$, O. Adejoro ${ }^{2}$, B. Chastek ${ }^{2}$, G. Chun ${ }^{3}$, J.B. Palmer ${ }^{3} .{ }^{1}$ University of Utah School of Medicine, Salt Lake City, UT; ${ }^{2}$ Optum, Eden Prairie, MN;

${ }^{3}$ Novartis Pharmaceuticals Corporation, East Hanover, NJ, United States

Background: Biologic therapy used for the treatment of active psoriatic arthritis (PsA) can sometimes be augmented by adding non-biologic medications and/or 